\title{
William Bradley Coley, MD, and the phenomenon of spontaneous regression
}

\section{Leonard F Vernon}

Sherman College of Chiropractic, Spartanburg, SC, USA
Correspondence: Leonard F Vernon I Market Street, Suite C, Camden, NJ 08102, USA

Tel +l 6092303256

Fax + I 85633809129

Email drvernonchiro@aol.com
This article was published in the following Dove Press journal: ImmunoTargets and Therapy

\begin{abstract}
The standard definition of spontaneous regression (SR) of cancer is as follows, “...when a malignant tumor partially or completely disappears without treatment or in the presence of therapy which is considered inadequate to exert a significant influence on neoplastic disease." SR is also known as Saint Peregrine tumor, the name taken from a young priest, Peregrine Laziosi (1260 [5]-1345, exact date is unknown), who had been diagnosed with a tumor of the tibia. The mass eventually grew so large that it broke through the skin and became severely infected. The available treatment for this condition was limited to amputation. Historical records report that on the day of surgery, physicians found that the tumor had disappeared and reportedly never returned. To date, the medical literature consists only of individual case studies and overviews of this phenomenon. The most cited work on the subject was done by surgeons Tilden Everson and Warren Cole who reviewed 176 published cases of SR from 1900 to 1960 . While a percentage of these were found not to be cases of $\mathrm{SR}$, there remained a number of unexplained cases. A frequent theme in many cases of SR is the co-occurrence of infection. Given the current interest in immunotherapy in the treatment of cancer, this article discusses one of the very early pioneers of this theory, William Bradley Coley, MD, a surgeon who was clearly ahead of his time. Ostracized by colleagues for his belief that stimulation of the immune system could in fact produce a regression of cancer, Coley remained convinced that his theory was right and, while he was not familiar with cytokines such as tumor necrosis factor (TNF), interferons, and streptokinase, he knew instinctively that an innate immune response was taking place.
\end{abstract}

Keywords: autoimmunity, cancer, fever, infection, immunotherapy, tumor, cytokines

\section{Introduction}

There is at bottom only one genuinely scientific treatment for all diseases, and that is to stimulate the phagocytes. The Doctor's Dilemma, George Bernard Shaw.

In the last 50 years, there have been few reviews of the literature on spontaneous regression (SR). One of the earliest was by Cole and Everson in $1956,{ }^{1}$ followed by a more extensive analysis published in 1968. Their examination included published cases, personal communications, and their own patient files from the period of 1900 to 1965. Utilizing a strict definition of SR, they yielded 176 cases. Cases that could not be confirmed were eliminated, as were cases in which any form of treatment capable of bringing about a regression had been used. Additionally, cases of leukemia and lymphoma, as well as retinoblastoma, were omitted, the latter because histological evidence 
confirming the presence of this cancer was seldom available. ${ }^{2}$ In 1990, a comprehensive collection of previous literature surveys, with the addition of newer published cases, was compiled by Challis and Stam. ${ }^{3}$ The authors concluded that

"the literature on the spontaneous regression of cancer is still unable to provide unambiguous accounts of the mechanisms operating to affect these regressions". ${ }^{3}$

Spontaneous tumor regression remains a very rare phenomenon, with an incidence rate of one out of every 60,000100,000 cases. $^{4}$

An historical look at phenomenon known as SR yields some clues to its causes. Most medical historians begin with the story of Peregrine Laziosi (1260 [5]-1345). At some point, this early priest noticed a large growth on his leg, apparently emanating from the tibia (there are conflicting reports as to which leg). Diagnosed by physicians as a malignant mass, it was determined that his only option was to undergo amputation. While waiting for the surgery to take place (again, the facts regarding the time frame between diagnosis and remission are lacking), the mass broke through the skin, and the surrounding tissue became ulcerated and exuded a foul-smelling pus. The stench was so overpowering that friends who were taking care of him could only remain nearby for a limited amount of time. Although there is no report of the patient being febrile, the description of the symptoms strongly suggests a severe bacterial infection.

When the day of surgery arrived, and the surgeons began to examine Laziosi, the tumor was found to be in regression. It eventually healed completely and never recurred. Laziosi lived to age 85 years and eventually was canonized as Saint Peregrine in 1726. Today, he is recognized by the Roman Catholic Church as the Patron Saint of cancer patients. Tumors that undergo SR are now known as Saint Peregrine tumors. Although skeptics could argue that this was merely an isolated event or a misdiagnosis of a malignancy by physicians who were trained in the 1300s and lacked the benefit of histological examination, the diagnosis - or perhaps misdiagnosis - is not as significant as the fact that SR of the growth occurred in the presence of an obvious infection process.

A significant number of published cases of SR of both tumors and hematological cancers appear to have occurred concomitant with infection, ${ }^{5,6}$ including diphtheria, gonorrhea, hepatitis, influenza, malaria, measles, smallpox, syphilis, and tuberculosis. ${ }^{7,8}$ Although occurring in an era prior to the knowledge of microorganisms, observation of cause and effect was noted in the very early published works. The first evidence of the treatment of cancer using microorganisms can be seen in the Iberian papyrus (1550 BC). ${ }^{9}$ The Egyptian physician Imhotep (2600 BC) used a poultice, with an incision and drainage, for the treatment of a tumor. The goal of this treatment was to facilitate the development of infection in the location of the lesions, with the goal of achieving tumor regression.

During the 17th and 18th centuries, various forms of immunotherapy to treat cancer became widespread. ${ }^{10,11}$ In the early 1900s, Paul Ehrlich reasoned that it was the body's own immune system that prevented cancer from being a more common malady. ${ }^{12}$ While the details of Ehrlich's targeted therapy (magic bullet) theory, for which he was ostracized by his colleagues, are beyond the scope of this article, suffice it to say that Ehrlich's theory remained dubious for over half a century, until researchers began to have a better understanding of the immune system and tumor antigens were discovered. ${ }^{13,14}$

While a detailed understanding of how the immune system functioned and why it had ability to fight cancer was unknown, there were those who recognized that the stimulation of the immune system could stimulate an antitumor response. Among these was William Bradley Coley, MD. Today, Coley is often described as the founder of modern immunotherapy, which has become a major cancer treatment.

\section{William Bradley Coley, MD, the early years}

William Bradley Coley was born in the Connecticut shoreline village of Saugatuck, just outside of Westport, on January 12, 1862. His parents Horace Bradley Coley and Clarina Wakeman Coley had a family lineage that dated back to the early part of the 17 th century and included religious leaders, schoolmasters, and owners of large farms from the west of England. Numerous biographies indicate that as a boy, Coley always wanted to attend Yale University and, in 1880, he received his acceptance to that institution. During his time off from his studies, he worked as a farm hand for neighboring farmers for $\$ 3.50$ per day or for his father and grandfather for no pay. He completed his undergraduate education and graduated from Yale in 1884.

Coley's route to a medical career was somewhat circuitous in that following his graduation, he relocated to Portland Oregon where he taught Greek and Latin at the Bishop Scott Government School. Two years later, he returned to his New England roots to attend Harvard Medical School. He completed what was at that time a 3-year program in just 2 years, receiving his medical degree in 1888 . He was awarded honorary Master's degree in 1910 from both institutions for his work in advancing surgery. ${ }^{15}$ 
In 1888, following a competitive examination for the limited available positions, Coley secured an internship at New York Hospital, where he trained under the auspices of two of the most prominent surgeons in New York, NY, USA, Dr William T Bull and Dr Robert F Weir, both later became involved in and played significant roles in Coley's research. In 1890, he obtained staff privileges at the Hospital for the Ruptured and Crippled, where, upon the death of Dr Bull in 1890 , he was given the title of attending surgeon. In 1924, he was named Surgeon in Chief of the hospital simultaneously holding the position of staff surgeon at New York Cancer Hospital (now Memorial Sloan Kettering Cancer Center). ${ }^{16}$ His academic appointments included clinical professor of surgery at Cornell University Medical School (1909) and clinical professor of cancer research at the same institution (1915).

Although educational pursuits and clinical work consumed most of Coley's time, he was still a young 22-year-old male who was not about to exclude females from his life and one in particular caught his eye, 18-year-old Alice Lancaster, a student at Miss Nott's Boarding School in New Haven, CT, USA. The two began dating in 1891 and they got married in 1894. Their first residence was a walk-up apartment in New York, NY, USA, where a year later, they had a son, Bradley Lancaster Coley. Coley's increasing prominence as a surgeon had caused his income to increase significantly, and by 1902 , his income was $\$ 33,000$, equivalent to $\$ 892,088.69$ in today's dollars. ${ }^{17}$ This financial and professional success allowed the family to relocate to a large brownstone at East 35th Street in New York, NY, USA.

\section{William Bradley Coley, the surgeon}

Among Coley's earliest accomplishments was his development of a surgical technique to treat abdominal hernias in children. The earliest mention in the US literature of the use of surgery in the repair of hernias in children was reported by Coley and his mentor William T Bull, MD, in 1898, when they wrote of the disappointing results of the current surgical procedures being used. Their paper, published in the Annals of Surgery, reported that of the 19 cases of hernia in children who had undergone surgery, $>50 \%$ had suffered a relapse within the first year, these disappointing results resulted in the abandonment of hernia surgery in children. ${ }^{18}$

During this same period, Europe saw the first efficient inguinal hernia repair. In 1884, a new surgical procedure that eliminated the need for a reinforcement prosthesis (the common practice in hernia surgery at the time) was introduced by Edoardo Bassini. Bassini's technique involved reconstructing the inguinal canal with sutures only. ${ }^{19}$ Although the procedure became common in Europe, it was more than a decade before it was introduced in the USA. Among the first to perform the procedure in the USA was Coley, who in 1899 operated on a 15-year-old boy using the Bassini procedure at the Hospital for the Ruptured and Crippled. The procedure eventually became the procedure of choice among US surgeons. Coley went on to perform the procedure hundreds of times, and the hospital's Hernia Department, having performed thousands of procedures, became a major treatment center for hernias in the USA. ${ }^{16}$ While Coley's surgical skills were widely admired by peers as well as his patients, it was his cancer research for which he was both ridiculed and remembered.

\section{Understanding the emperor of all maladies}

Coley's biographer Stephen Hall states that the inspiration for Coley's interest in the treatment of cancer began in the late summer of 1890. Elizabeth Dashiell, a 17-year-old girl, who became known to Coley and his staff as Bessie, presented to his office, she had injured her hand, and a lump had developed at the injury site. Although initially appearing as a relatively minor injury, she suffered increasing pain and had visited numerous other physicians without a diagnosis.

Coley's initial diagnosis was an infection. However, he still decided to perform a biopsy and the result revealed that Bessie was in fact suffering from a sarcoma. In a period before the use of radiation and chemotherapy, the only treatment available to Bessie was amputation, with the goal of preventing the spread of the cancer. However, following the amputation, Coley realized that the disease had already metastasized to her lungs and liver. In his book A commotion in the blood: life, death, and the immune system, Hall described the scene thusly, "On Jan. 23, 1891, less than 6 months after first seeing Coley - and following what was described as a wrenching and painful period - Bessie died with Coley by her side". ${ }^{20}$

Coley was so affected by Bessie's death that it motivated him to increase his research in cancer. While cancer was still a poorly understood disease at this time, Coley was a student of Darwin and his one takeaway from his readings was that when there is a biological exception to a rule, "... ask yourself: Why has this happened?", Coley began an exhaustive search of the New York Hospital's archives, digging through dozens upon dozens of old records hoping to find information to help him better understand cancer. His persistence paid off when he located the case of a German immigrant named Fred Stein. ${ }^{21}$ 
In 1883, Fred Stein was admitted to New York Hospital because of a tumor on his neck. There had been multiple attempts at removing the tumor; however, it reappeared not long after being removed. Following on such surgery, Stein developed an infection and the organism was determined to be Streptococcus pyogenes. Because it was another 45 years before Alexander Fleming's discovery of penicillin, his treating physicians believed that his fate was sealed and death would occur shortly, but Stein did not die; in fact, his tumor resolved and he was subsequently discharged. Now, almost a decade later, Coley speculated as to whether Stein was still alive.

Coley's odyssey to locate Stein nearly defines the term "gumshoe detective". During this period, most German immigrants resided in the tenement flats of the Lower East side of Manhattan. Going door to door, Coley inquired about a man named Fred Stein (a common German surname) who had a distinctive scar across his neck. After several weeks of searching, Coley found him alive and cancer free. ${ }^{22}$ It was then that Coley hypothesized that Stein's Streptococcus infection had reversed the cancer and he now began to wonder if by deliberately injecting cancer patients with this bacterium, he was able to obtain a reproducible result.

In an era before informed consent and institutional review boards, clinical research was frequently conducted under the guise of medical care. Coley decided that he would test his theory on the most seriously ill patients first. ${ }^{23} \mathrm{His}$ first patient was an Italian immigrant whose name is recorded simply as Zola. Zola's cancer was in the throat and prevented him from speaking or eating; it frequently interfered with breathing. Coley began his experimental treatment by making small incisions in Zola and then rubbing the Streptococcus pyogenes into the wound. After months of attempting to induce a systemic response with little result, Coley procured a more virulent strain of the bacteria and introduced it directly into Zola's tumor, at which point the patient became extremely ill. For a short time, Coley thought that he might have overdone it and that the bacteria would kill Zola, but within 24 hours, the tumor began to liquefy and resolve and eventually Zola completely recovered.

While Coley was not the first to attempt to cure cancer using a bacterial infection (that distinction belongs to German physician Wilhelm Busch), he was the first to utilize the procedure systematically on a large number of patients. While Coley's theory was celebrated in many medical quarters in the USA and Europe, not everyone was impressed. The old-line orthodox medical community became increasingly skeptical, citing the treatment's unpredictable effect, mainly a very high fever on a host already weakened by cancer. Additionally, when the treatment did work, its mechanism of action was not understood. Because it was many decades before the immune system was understood, this was a question that not even Coley himself could answer. The inability to answer these questions and the intense labor and excessive expense involved in preparing the vaccine as well as the introduction of radiation therapy in the 1900 s combined to cause Coley's theory of stimulating the immune system to fight cancer disappeared from medicine's armamentarium of treatment options. ${ }^{24-26}$

An additional reason for the lack of popularity of Coley's theory was its limited effectiveness on a broad range of cancers: it was mainly effective against sarcoma, which represents only a small percentage of all cancers. Still, perhaps the most challenging obstacle was the period in which Coley made his discovery. Medical thinking in this period gave very little credit to the human body's ability to cure itself, instead believing that outside intervention was necessary for healing to occur, a dogma that persisted in oncology circles as late as the 1980s. As late as 2001, many oncologists remained skeptical of immunological measures in the treatment of cancer, even with medicines' ability to now manipulate fevers and mounting evidence showing that fever could cause tumor cell death. ${ }^{27}$

\section{The birth of immune therapy}

While there is a much clearer understanding of fever and its ability to stimulate the immune system, the exact mode of action of Coley's toxins remains unclear; however, most experts agree that what is occurring is what is now known as a cytokine reaction. Because Coley used highly pathogenic bacteria and injected them directly into inoperable tumors, the possibility that the microbes themselves might have been involved in fighting the cancer cannot be ruled out. An example of this can be seen in Salmonella, which is known to have the capacity to colonize and eliminate solid tumors. In 2017, researchers from the Department of Experimental Therapeutics of the Beckman Research Institute of City of Hope in California, in a paper entitled "Utilizing Salmonella to treat solid malignancies", found that Salmonella enterica seovar Typhimurium not only had antitumor effects but also could be a potential vector to carry other materials into a tumor. ${ }^{28}$ In 2012, researchers working in the Section of Molecular Oncology and Immunotherapy in Rostock, Germany, systematically analyzed tumoricidal as well as immunostimulatory effects of the historical preparation Coley's toxin, a vaccine made of heat-inactivated Streptococcus pyogenes and Serratia 
marcescens. Antitumoral effects following local therapy were primarily accompanied by stimulation of innate immune mechanisms, thus implying that molecules still active in the heat-inactivated microbial mixture were responsible for such an effect. While the December 2013 edition of Science dedicated its cover to "Cancer Immunotherapy", calling it "...the breakthrough of the year", ${ }^{29}$ the fact is that this breakthrough had occurred $\sim 100$ years earlier.

Following Coley's death in 1936, his daughter Helen Coley Nauts began to write a biography of her father. It was during her research that she unearthed $\sim 1000$ files on patients who had been treated by her father and his "Coley's toxins". Helen spent years looking at and analyzing the data, concluding that her father had a very high rate of success in the treatment of certain tumors; in fact, many results were better than the current treatments of the era. However, her attempts to get the scientific community to listen fell on deaf ears.

In 1953, with a small grant, Helen Coley Nauts started the Cancer Research Institute (CRI), with a mission statement of “...understanding the immune system and its relationship to cancer". The greatest obstacle to the acceptance of Coley's work was the American Cancer Society. From 1965 to 1975 , they put him and his treatment on their "Unproven methods of cancer management" blacklist. It was only the determined work of Helen Coley Nauts and - very importantly - Lloyd J Old of Sloan Kettering Institute that got Coley's toxins removed from the list. This allowed the further development of cancer immunotherapy unimpaired by the charge of "quackery". In 1998 when Bruce Buetler, MD, and his colleagues at the Scripps Institute in La Jolla, CA, USA, showed that the bacterial toxin lipopolysaccharide can activate immune system cells, toll-like receptors (TLRs). These in turn are effective in killing cancer cells and tumors. ${ }^{30}$ These findings confirmed Coley's theories giving him the recognition he deserved. Coley's legacy continues through the funding of immunotherapy research by the CRI with many of the $>25$ cancer immunotherapies on the market today having been developed by researchers (some of whom were postdoctoral fellows at CRI) who received early seed money from Helen Coley Nauts's CRI. ${ }^{31}$ A schematic summary of events is provided in Figure 1.

\section{Disclosure}

The author reports no conflicts of interest in this work.
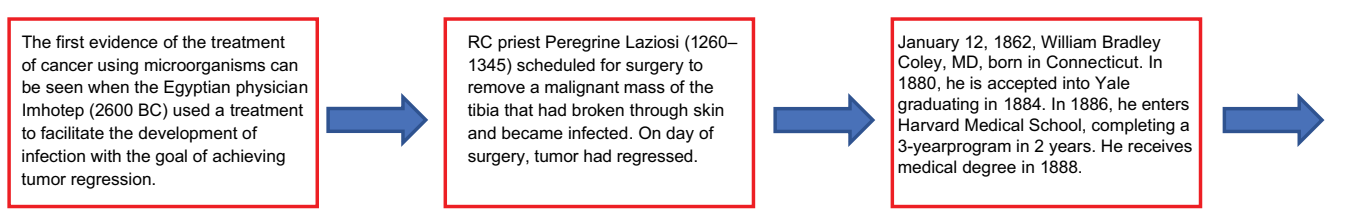

Coley develops a surgical technique o treat abdominal hernias in children. While his surgical skills were widely admired, it would be his were widely admired, it would be his
cancer research for which he would cancer research for which he would
be both ridiculed and remembered.
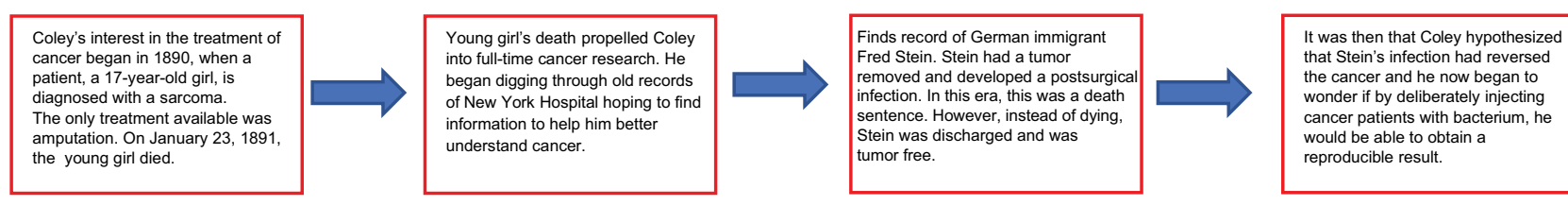

reproducible result.
Anecdotal cases of SR begin to appear in the literature in the early 19th century. The first large series of cases of SR of cancer was reported by Rohdenberg in 1918. The greatest number of $S R$ is seen in patients with a febrile process.
Coley now introduced a more virulent strain of the bacteria. The patient became extremely ill. Coley
thought that the bacteria would kill the patient, but in 24 hours, the tumor began to resolve, and the patient would completely recover.

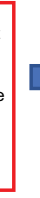
attempting to induce a systemith
response with little result.
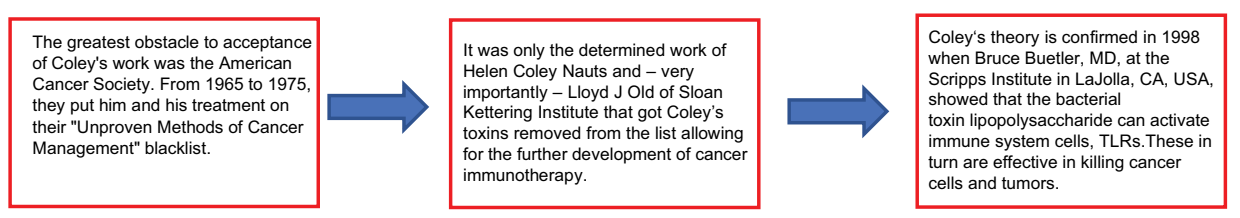

Figure I How immunotherapy to treat cancer was born.

Abbreviations: SR, spontaneous regression; TLRs, toll-like receptors. 


\section{References}

1. Cole WH, Everson TC. Spontaneous regression of cancer: preliminary report. Ann Surg. 1956;144(3):366-383.

2. Everson TC, Cole WH. Spontaneous Regression of Cancer. Philadelphia, PA: JB Saunders \& Co.; 1968.

3. Challis GB, Stam HJ. The spontaneous regression of cancer: a review of cases from 1900 to 1987. Acta Oncol. 1990;29(5):545-550.

4. Cole WH. Efforts to explain spontaneous regression of cancer. J Surg Oncol. 1981;17(3):201-209.

5. Sindelar WF. Regression of cancer following surgery. Natl Cancer Inst Monogr. 1976;44:81-84.

6. Cann SAH, van Netten JP, van Netten C. Dr William Coley and tumour regression: a place in history or in the future. Postgrad Med J. 2003;79(938):672-680.

7. Rohdenburg G. Fluctuations in the growth energy of malignant tumors in man, with especial reference to spontaneous recession. J Cancer Res. 1918;3(2):193-225.

8. Wiernik PH. Spontaneous regression of hematologic cancers. Natl Cancer Inst Monogr. 1976;44:35-38.

9. Jessy T. Immunity over inability: the spontaneous regression of cancer. J Nat Sci Biol Med. 2011;2(1):43-49.

10. Thomas JA, Badini M. The role of innate immunity in spontaneous regression of cancer. Indian J Cancer. 2011;48(2):246-251.

11. Kucerova P, Cervinkova M. Spontaneous regression of tumour and the role of microbial infection - possibilities for cancer treatment. Anticancer Drugs. 2016;27(4):269-277.

12. Schreiber RD, Old LJ, Smyth MJ. Cancer immunoediting: integrating immunity's roles in cancer suppression and promotion. Science. 2011;331(6024):1565-1570.

13. Old LJ, Boyse EA. Immunology of experimental tumors. Annu Rev Med. 1964;15:167-186.

14. Tan SY, Grimes S. Paul Ehrlich (1854-1915): man with the magic bullet. Singapore Med J. 2010;51(11):842-843.

15. Rites tomorrow for Dr. W. B. Coley; eminent authority on cancer and abdominal surgery, 74, won many honors. The New York Times, 1937 Apr 17, p. 21.

16. Levine DB. The hospital for the ruptured and crippled: William Bradley Coley, third surgeon-in-chief 1925-1933. HSS J. 2008;4(1): $1-9$.
17. $\$ 33,000$ in $1902 \rightarrow 2016$ | Inflation Calculator [webpage on the Internet]." FinanceRef Inflation Calculator, Alioth Finance, 2018. Available from: http://www.in2013dollars.com/1902-dollars-in2016? amount=33000. Accessed February 5, 2018.

18. Bull WT, Coley WB. II. Observations upon the operative treatment of hernia at the hospital for the ruptured and crippled. Ann Surg. 1898;28(5):577-604.

19. Elsebae MM, Nasr M, Said M. Tension-free repair versus Bassini technique for strangulated inguinal hernia: a controlled randomized study. Int J Surg. 2008;6(4):302-305.

20. Hall SS. A Commotion in the Blood: Life, Death, and the Immune System. New York, NY: Henry Holt; 1997.

21. Target Health Inc [webpage on the Internet]. William Bradley Coley MD - Pioneer of Immunotherapy. 2017. Available from: https://www. targethealth.com/post/william-bradley-coley-md-pioneer-of-immunotherapy. Accessed December 17, 2017.

22. Mack M [webpage on the Internet]. Was the Cure for Cancer Discovered More Than a Century Ago? . 2016. Available from: https://www. mesotheliomahelpnow.com/blog/cure-cancer-discovered/. Accessed December 17, 2017.

23. Miller FG. Clinical research before informed consent. Kennedy Inst Ethics J. 2014;24(2):141-157.

24. Hess DJ. Suppression, bias, and selection in science: the case of cancer research. Account Res. 1999;6:245-257.

25. Hobohm U. Healing heat: harnessing infection to fight cancer. Am Sci. 2009;97(1):34-41.

26. Mellman I, Coukos G, Dranoff G. Cancer immunotherapy comes of age. Nature. 2011;480:480-489.

27. Hobohm U. Fever and cancer in perspective. Cancer Immunol Immunother. 2001;50(8):391-396.

28. Ebelt ND, Manuel ER. Utilizing Salmonella to treat solid malignancies. J Surg Oncol. 2017;116(1):75-82.

29. Couzin-Frankel J. Breakthrough of the year 2013. Cancer immunotherapy. Science. 2013;342(6165):1432-1433.

30. Schmidt C. Immune system's toll-like receptors have good opportunity for cancer treatment. J Natl Cancer Inst. 2006;98(9):574-575.

31. Cancer Research Institute [webpage on the Internet]. FDA-Approved Cancer Immunotherapies and CRI's Impact. 2015. Available from: https:/www.cancerresearch.org/blog/april-2015/fda-approved-cancerimmunotherapies-cris-impact. Accessed December 20, 2017.
ImmunoTargets and Therapy

\section{Publish your work in this journal}

ImmunoTargets and Therapy is an international, peer-reviewed open access journal focusing on the immunological basis of diseases, potential targets for immune based therapy and treatment protocols employed to improve patient management. Basic immunology and physiology of the immune system in health, and disease will be also covered. In addition, the journal will focus on the impact

\section{Dovepress}

of management programs and new therapeutic agents and protocols on patien perspectives such as quality of life, adherence and satisfaction. The manuscrip management system is completely online and includes a very quick and fair peer-review system, which is all easy to use. Visit http://www.dovepress.com/ testimonials.php to read real quotes from published authors. 